\title{
1 \\ Dealing with climate change on small islands: Towards effective and sustainable adaptation?
}

\author{
Carola Klöck and Michael Fink
}

Small islands are so-called hotspots of climate change. Here, the adverse effects of sea-level rise, increasing temperatures, and changing weather patterns are already felt, making adaptation urgent (Mimura et al., 2007; Nurse et al., 2014). But while small islands may be uniquely impacted by the adverse effects of climate change, they are also uniquely resilient. Small islands are not only at the forefront of climate change impacts, they are also at the forefront of climate change responses. Island societies have long histories of resilience, of surviving, if not thriving, in resource-limited, dynamic, and isolated environments (Campbell, 2009; Nunn \& Kumar, 2018). Over generations, sometimes over millennia, they have developed a wide range of practices to deal with climate variability and extreme weather events and incorporated them into cultural practices, myths, and songs. From this perspective, islands are traditionally "sites of resilience" (Campbell, 2009, p. 85) and "agents of knowledge production and territorial transformation" (Ratter, 2018). Accordingly, islanders "must be looked to and supported as inspiring champions of livelihood resilience and adaptation to climate change and disasters," as De Souza and colleagues (2015, p. 1) write (see also e.g. Barnett \& Campbell, 2010).

Small islands hold valuable lessons for both adaptation success and adaptation failure. Not every historical experience and traditional coping strategy is helpful for

Cite this article: Klöck, C. \& Fink, M. (2019): Dealing with climate change on small islands: Towards effective and sustainable adaptation? In: Klöck, C. \& Fink, M. (eds.): Dealing with climate change on small islands: Towards effective and sustainable adaptation? (pp. 1-15). Göttingen: Göttingen University Press. https://doi.org/10.17875/gup2019-1209 
dealing with current and future climate change, and not every so-called adaptation measure is effective. Quite to the contrary, some would argue that most adaptation interventions have failed in small island contexts (Nunn \& Kumar, 2006). Why is this the case? What has worked, when, and why? Where do we see adaptation to climate change occurring in small island states? What types of measures are taken, by whom, and why?

The present volume seeks to explore adaptation to climate change in small islands across the world's oceans. We want to focus attention on the resilience, strengths, and agency of small island states - which may better be referred to as "big ocean sustainable states," or "BOSS" (UNESCO, 2017) - but at the same time acknowledge the specific challenges that climate change poses to small islands. As the contributions to this volume highlight, islands are extremely diverse, in terms of geophysical, cultural, and socio-economic characteristics, climate change impacts, as well as perceptions of and responses to change, at different levels. This diversity confirms the need for context- and place-specific solutions; one-size-fits-all solutions do not exist. Nevertheless, we consider that the diverse experiences of islands hold valuable lessons: small islands can learn from one another - and we can all learn from small islands.

This inter-island and inter-regional exchange has so far been marginal. While the specific circumstances of small islands have received significant political and academic attention (Mimura et al., 2007; Nurse et al., 2014), much of this research focuses on single case studies; comparative work across different islands is relatively rare (Klöck \& Nunn, 2019). The present volume adds to recent efforts at bringing together individual case studies (Moncada, Briguglio, Bambrick, \& Kelman, 2018; Walshe \& Stancioff, 2018). We recognise the need for dialogue: across geographical scales and regions; across academic disciplines; as well as across the science-policy divide. The volume therefore brings together scholarship on and from the three island regions: the Caribbean, the Pacific, and the Indian Ocean. The contributions in this volume include work from geography, anthropology, political science, psychology, and philosophy. Empirically, the focus is on the Pacific where most small island research is located (Klöck \& Nunn, 2019) - but some chapters also focus on the Caribbean, the Indian Ocean, or small islands in general.

The volume has its roots in a workshop held in July 2018 in Hannover, with financial and organisational support from the Volkswagen Foundation. Over three days, more than 30 workshop participants discussed the challenges and opportunities of climate change adaptation; commonalities and differences between islands and island regions; research gaps; as well as venues for dialogue between policy and practice (Klöck, Debelts, \& Fink, 2019). Many of the workshop contributions are included in the present volume, in revised form. We would like to express our gratitude to all workshop participants for the intense and fruitful discussions in Hannover, and in particular thank all contributors to this volume - their contributions, as authors and/or as peer reviewers, are much appreciated. 
Three areas of concern structure the present volume: governing long-term adaptation; the role of culture, knowledge, and perceptions; and migration and (im)mobility. In the remainder of this introduction, we outline why these areas are of particular relevance to small island states, and how the contributions to this volume address some of the research gaps in these areas.

\section{Governing and funding long-term adaptation}

For a long time, vulnerability and adaptation have been dominated by the systemic hazards approach, or a focus on physical exposure and technical solutions (Adger, 2006; Bassett \& Fogelmann, 2013). In contrast, the social vulnerability approach highlights (lack of) human agency as critical for vulnerability and takes into account socio-economic drivers of vulnerability. It thus emphasises sensitivity to climate change impacts and adaptive capacity, in the terminology of the hazards approach (Keck \& Sakdapolrak, 2013; Mikulewicz, 2018). From this perspective, adaptation is first and foremost a political process (Eriksen, Nightingale, \& Eakin, 2015). Further, adaptation is long-term and transformational, in the sense of addressing underlying social, economic, and political drivers of vulnerability. Adaptation thus goes beyond short-term coping, and requires holistic approaches; rather than tackling physical climate change impacts in isolation, adaptation seeks to address inequities and improve the wellbeing of people and societies (Klepp \& ChavezRodriguez, 2018).

Such a critical approach, or political ecology lens, foregrounds many of the inherent difficulties and challenges of adaptation. These include for example tensions between typically short-term political considerations, and the long time horizons of effective and transformational adaptation. A specific challenge of adaptation in Small Island Developing States (SIDS) relates not only to the often-times lacking political will to implement long-term adaptation measures, but also to the human and financial constraints. These are particularly acute in the context of small islands with their small populations, economies, and administrations. Adaptation hence often depends on the availability of external (aid) funding, which comes with its own challenges, including the short time horizons of aid-funded (pilot) projects, significant year-to-year fluctuations of flows, and considerable administrative burdens for planning and reporting (Barnett \& Campbell, 2010; Overton, Prinsen, Murray, \& Wrighton, 2012; Dornan \& Pryke, 2016).

Part I of this volume explores some of these constraints, as well as ways to overcome them, from diverse vantage points. In the first chapter, Patrick D. Nunn and Karen E. McNamara examine why adaptation interventions in island contexts often fail, and explore how more long-term transformational change could be achieved. 
The authors start from the assumption that many coastal areas - where most settlements, infrastructure, and economic activities are concentrated in small islands - will likely become uninhabitable over the coming decades. Although relocation away from the most vulnerable to less vulnerable locations is thus unavoidable, most responses to sea-level rise, coastal erosion, and flooding to date have sought to 'protect', that is, to stabilise the current coastline and maintain current settlements and infrastructure, through seawalls and other hard coastal protection measures. While such hard measures may work in more iconic and wealthier locations, such as capital cities, they often fail in rural and poorer locations, as is the case in many SIDS, where financial and technical resources are limited, where climate change perceptions and decision-making largely follow spiritual and traditional approaches, and where short-term concerns dominate.

In this context, 'retreat' rather than 'protect' seems the more sustainable, effective and long-term response - and hence can be classified as 'transformational' change. However, relocation away from exposed (coastal) areas is problematic, for a number of reasons, despite there being cases of success and even avoidance altogether. Because of this, and based notably on the experience of Fiji, where several villages have been, or are in the process of being, relocated, the authors identify factors that can make relocation successful, and hence transformational. In particular, the affected population needs to drive the entire relocation process, from the planning through to the implementation as well as monitoring and evaluation phases.

Virginie K. E. Duvat and Alexandre K. Magnan also consider relocation to be inevitable under some conditions, but their chapter at the same time points out that local adaptation is still often possible, even in the context of atolls, which are among the areas most vulnerable to the adverse impacts of climate change.

Their chapter strongly calls for nature-based solutions (NBS) to maintain, strengthen, and re-establish natural ecosystems, notably the atoll reef-island system. Empirical data from the Maldives - which is one of four countries worldwide that consists exclusively of low-lying atolls - shows that NBS can work: healthy coral reefs protect the coast and supply sediment to islands where (i) sediment transport pathways are kept clear and (ii) accommodation space remains available along the coast for sediment accumulation. However, on many islands, human activities have undermined the coastal protection services delivered by the reef ecosystem. The degree of undermining of these services by human disturbances currently largely determines the degree to which atoll islands are able to respond to climate-related pressures. Those islands that are still able to withstand sea-level rise (due to limited human undermining of these services) will likely continue to do so for at least the next few decades. The more disturbed the island, the lower the potential for NBS, and the higher the need for alternative solutions, including engineered solutions and - from the middle of the $21^{\text {st }}$ century - internal and international migration under worst-case scenarios 
There is a continuum of adaptation strategies for atolls that must be placespecific and tailored to the specificity of each island. The authors conceptualise this continuum as a five-pillar adaptation pathway, along which the role of NBS decreases, while the role of engineering and migration increases.

Most adaptation measures depend on the availability of external financing. While such funding is increasing, it is insufficient to meet adaptation needs. How then should such scarce finances best be distributed? Christian Baatz and Michel Bourban examine this question of distribution from a justice perspective, and argue for democracy as an appropriate additional criterion.

Research and politics consider that adaptation financing needs to be allocated to 'particularly vulnerable' countries, such as the SIDS. However, this vulnerability criterion is problematic for various reasons (such as the difficulty of measuring it), and therefore needs to be complemented with additional criteria. Cost effectiveness - maximising impact - is proposed in this context, but Baatz and Bourban demonstrate that this criterion is also problematic and difficult to measure. Instead, the authors argue for democracy. Democratic countries do not only tend to use funding more effectively, but also allow affected populations - those who are entitled to funding by virtue of their jeopardised human rights - to participate in decision-making on how funding is spent. Democracy, as measured for example by VDem indices, could thus also guide the allocation of adaptation financing, and influence not only how much financing vulnerable countries receive, but also to what extent that financing is conditional.

Beyond finance, political will as well as administrative capacity constrain effective adaptation, in particular in small islands, where small population sizes translate into small administrations. Harvesting synergies would be beneficial but is rare in practice, as the chapter by Michelle Scobie shows. The chapter uses the example of St. Lucia to identify interlinkages between issue-areas and levels of governance that can help overcome silos and address multiple goals at once.

Much (environmental) policy-making and implementation happens in silos, despite potential similarities and synergies. For example, climate change has much to do with disaster risk reduction or (sustainable) development more broadly. At the same time, policies are formulated at different levels, in global negotiations, regional programmes, or national plans. Interlinkages can help connect these processes and levels. In her review of policy documents at different levels, Scobie finds many thematic points of convergence, but also different priorities. Regional (Caribbean) and national (St. Lucian) documents put more emphasis on some areas such as finance, but use the language of global agendas, such as the Sustainable Development Goals, not least to attract funding. Even if many cross-references and similarities are implicit only, there are efforts to overcome thematic silos. In this context, St. Lucia dissolved its climate change unit, in an effort to integrate climate change into each ministry's work. 
Finally, Adelle Thomas examines research on adaptation planning, also in the Caribbean. Her chapter draws on the Caribbean Climate Risk and Adaptation Tool, CCORAL, developed by the Caribbean Community Climate Change Centre.

The CCORAL is a widely used policy tool that seeks to mainstream climate change into planning activities across the region. Based on this tool, Thomas conceptualises an adaptation planning cycle: within the wider adaptive space, or overall context, adaptation thus follows six distinct steps, from vulnerability and risk assessment through to monitoring and evaluation. To what extent are these steps followed? Through a review of peer-reviewed literature, the chapter seeks to identify strengths and gaps in academic research that can in turn inform future research and adaptation planning and practice.

While there is a growing body of literature that examines adaptation, including adaptation planning, in the small islands of the Caribbean and beyond, this literature does not pay equal attention to the various elements of the adaptation policy cycle. A large number of studies assess climate change risks, impacts, and vulnerabilities, for specific countries and/or for specific sectors. Several studies also examine the overall adaptive space, and highlight in particular the role of perceptions and availability of data as constraints to adaptation. In contrast, very few studies, if any, examine how - and why - stakeholders identify adaptation options, or select and prioritise among these. Similarly, relatively little is known about implementation, and even less about the long-term effects and effectiveness of implemented measures. Although studies mention the importance of monitoring and evaluation, the literature review finds no study that specifically examines monitoring and evaluation methods and practices, beyond some technical reports. The chapter thus concludes with a call for more research into those elements of the adaptation planning cycle that have received scant academic (and possibly political) attention, but are just as important for effective and sustained adaptation as the first step of risk and vulnerability assessment.

\section{Cultures, perceptions, and knowledges}

Just as the climate is changing, so are island societies. Social, economic, and cultural changes are omnipresent, and interact with environmental changes - indeed, these two spheres are closely interrelated and sometimes even conceptualised as one (see Pascht and Hetzel below). This perspective aligns with the political understanding of adaptation outlined earlier. Adaptation is about risks, and therefore about values: What risks are acceptable? What is at risk? How should these risks be avoided, and at what costs? The answers to these questions are all mediated by culture (O’Brien \& Wolf, 2010; Adger, Barnett, Brown, Marshall, \& O'Brien, 2013). This cultural perspective, though neglected in much adaptation research, makes visible differences across and within islands, countries, and regions (Adger et al., 2013), for example in how people perceive changes. Such perceptions are 
crucial to understanding responses, for people will only act upon climate change if they perceive it as a risk (Lee, Markowitz, Howe, Ko, \& Leiserowitz, 2015). Beyond risk perception, action also requires perceived adaptive capacity: people need to feel empowered and able to act (Grothmann \& Patt, 2005). Such feelings of empowerment shape, and are shaped by, discourses and narratives. Hence, alternative framings to the widespread gloom-and-doom scenario of inevitable inundation are needed to facilitate agency.

Culture is also intimately related to local knowledge - also referred to as traditional or indigenous knowledge (Lauer, 2017; Nalau et al., 2018). Particularly in the Pacific, island societies have accumulated a large body of local knowledge to deal with climate variability, which is constantly changed and adjusted (Lauer, 2017). While there is consensus that such local knowledge and experiences hold valuable lessons for, and need to be integrated into, climate change adaptation, we should be careful not to view local knowledge as a panacea, and integrating it with Western science as necessarily easy and effective (Mercer, Dominey-Howes, Kelman, \& Lloyd, 2007).

Part II of this volume engages with a cultural understanding of climate change adaptation, and explores the role, variation, and effects of cultures, perceptions, and knowledges, with a focus on the Pacific.

First, Katharina Beyerl, Harald A. Mieg, and Eberhard Weber analyse perceptions of climate-related environmental changes in three Pacific island countries: Tuvalu, Samoa, and Tonga. Their chapter is premised on the assumption that risk perceptions matter, but that to date we have not paid enough attention to variations in perceptions. Accordingly, the chapter focuses on variation in perception across and within the three case countries.

Their large-N survey shows that respondents across the three countries have noticed changes in their environment, ranging from higher temperatures to sealevel rise, increased flooding, as well as changes in flora and fauna, and that they expect that most trends will intensify in the future. Yet, respondents' perceptions vary in terms of the specificity and severity of observed changes. For example, drought and sea-level rise were particularly prominent in Tuvalu, while increases in the intensity and frequency of extreme weather events have been noted more strongly in Samoa and Tonga.

This variance results in part from differences in weather conditions and geographies in the three countries, but is also explained by socio-economic factors. Notably, where respondents live (that is, settlement size and distance to the sea), how intensely they interact with their environment, and how religious they describe themselves to be are correlated with perceptions of change. When it comes to explaining observed changes, respondents are aware of the multiple causes and mainly attribute changes to careless and unsustainable human behaviour, rather than divine will, which is mentioned only occasionally. Comparative surveys help 
Carola Klöck and Michael Fink

to gauge where local priorities lie, which unsustainable behaviours contribute to local environmental changes, and thus how to shift to more sustainable practices.

The chapter by Hannah Fair shares the assumption that perceptions matter for climate change adaptation. In particular, the author examines the mediating role of religion and religiosity on climate change perceptions and adaptation, drawing on fieldwork in Vanuatu and with the Pacific Climate Warriors. While religion is often marginal in climate change adaptation discourse and practice, Fair calls for a spiritualisation of climate change, as a means to centre islander agency.

The Pacific is a deeply religious and spiritual region, which has often been seen as a hindrance to climate change adaptation. When changes are attributed to divine will, little can be done beyond prayer, resulting in faith-based apathy. Yet, Fair finds that the relations between trust in the divine, prayer, and agency are more nuanced. Many interviewees emphasise the 'sin' of carbon emissions, and take on responsibility. While such a local narrative stands against global discourses of climate justice, North-South divides, and differentiated responsibilities, it also enables local agency: Vanuatu becomes the centre not just of the problem but also of the solution. Finally, respondents also emphasise that God is with them in their suffering. This sense of God's protective presence also underpins Pacific climate activism, which is interpreted as a form of spiritual devotion, as "doing God's work".

Clearly, religion plays a role in climate change and adaptation in the Pacific, but different understandings of this link co-exist. Overall, these understandings emphasise and enable local agency, in different forms. Spiritualising climate change thus underpins an alternative, and more empowering, framing of climate change.

Desirée Hetzel and Arno Pascht also examine climate change adaptation in Vanuatu. Their chapter focuses on two villages - Siviri (Efate, close to Vanuatu's capital, Port Vila) and Dixon Reef (Malekula, in the north of Vanuatu) - where NGOs have organised workshops and training sessions to improve food security and to adapt to changing climate.

In both villages, inhabitants rely on agriculture and horticulture, which more frequent and/or intense cyclones such as Cyclone Pam (2015) and droughts threaten. Hetzel and Pascht hence explore how local villagers use, appropriate, modify, and/or reject innovative practices and methods taught in NGO workshops. They show that villagers are keenly interested in outside knowledge and experiment with new techniques, but may also decide against applying these techniques, temporarily abandon them, or resume them, as they see fit, and instead, or in parallel, turn to traditional practices. Village livelihoods are diverse and increasingly diversify in response to extreme weather events. Beyond diversifying their agricultural and horticultural practices, villagers also turn to the cash economy to purchase food. Such diversification processes, however, are not new; the NGO projects did not lead to significantly more diversification. From this point of view, adaptation is normal, and thus needs to be understood in a more holistic way that 
does not distinguish between the social, the physical, and the other-than-human spheres.

Finally, the chapter by Stefano Moncada and Hilary Bambrick turns to Rabi Island (Fiji). The authors explore responses to climate variability in coastal communities to understand to what extent current coping is conducive to long-term adaptation to climate change, and how development status affects the responses taken.

Rabi Island shares many of the climatic challenges of islands across the Pacific (and elsewhere), but its inhabitants are an ethnic minority in Fiji, being resettled from Banaba Island (Kiribati) as a result of phosphate mining. Despite this additional barrier, Rabi Islanders draw on a variety of livelihood resources to respond to different climatic and non-climatic shocks, such as cyclones, droughts, and lack of easy market access. While many of these response measures - for example reducing consumption and shifting to other foods in case of drought - are sustainable, they may better be qualified as short-term coping rather than long-term adaptation. Long-term measures - for example upgrading infrastructure and housing, or installing a water management system - are known, but lack of resources prevent their implementation, while limited market access means that the communities are unlikely to increase income. The authors therefore conclude that development deficits need to be addressed to help remote coastal communities deal with climate change.

\section{$3 \quad$ Migration and (im)mobility}

In the context of climate change, small islands are almost automatically linked to migration. The narrative of islanders "fleeing" their "drowning" islands has dominated public and media discourse (for a critical review of this discourse, see Farbotko, 2005, 2010, 2012). Reality on the ground is rather different. Migration has always been part of island life. Islanders migrate, temporarily or permanently, within and across national boundaries, for various reasons that can include employment, health, education, or social relations. Given that the decision to migrate is always a multi-dimensional one, it is difficult - if not impossible - to separate climate change from other drivers of migration. It also remains rather unclear to what extent climate-related or environmentally induced migration follows different migration patterns (Campbell, 2014). One difference is the potentiality of no return: while migrants usually uphold strong relations to their home village, island, or state, this may no longer be possible when entire villages or islands become uninhabitable.

Migration and mobility are generic concepts that include a range of distinct phenomena: short-term and short-distance displacement, such as evacuations before or after extreme weather events; planned relocation of individual households 
or entire communities over short distances; or temporary or permanent migration of individuals from rural outer islands to urban centres and capitals or across international borders (Campbell, 2010; McNamara \& Des Combes, 2015). The rubric of migration and mobility also includes "trapped populations" that want to leave but are unable to do so, for example because they lack the necessary resources. In contrast, the "voluntary immobile" could leave, but do not want to do so, for example because they have deep cultural and spiritual bonds to the land, even if that land may be under threat of becoming permanently inundated (Zickgraf, 2018).

The third and last part of this volume addresses these different phenomena of migration and (im)mobility. First, Carol Farbotko explores questions of ontological security, or the "security of being". Her chapter starts to unpack this concept, and calls for more research into ontological shifts and questions of being.

The author starts from the observation that climate change is often described and understood as an "existential threat", particularly in (but not limited to) the context of small islands like those in the Pacific. If one accepts that some places may become uninhabitable, what does this mean for the affected populations and their identity? As Farbotko writes, "Are we still who we were? Will we still be 'us' in the future?" These questions are particularly acute in the Pacific, where identity has traditionally been closely intertwined with the land, as evidenced in the concept of *banua. *Banua refers to place and people, and is shared across large parts of the Pacific. At the same time, it was the people of the Pacific that first sailed out of sight of land - a key moment not only for the history of humankind but also for ontological security, for the people sailed out of sight of known land, and into a "new world of being".

Climate change again threatens and changes ontological security, by threatening the land itself. This has profound implications for agency, as a stable sense of self - ontological security - underpins agency. In this context, Farbotko suggests that voluntary immobility may help maintain ontological security. When land continues to be inhabited by at least some, there remains a link, places of high cultural value can be maintained, and traditional knowledge can more easily be upheld and expanded.

Security has many dimensions. Eberhard H. Weber, Priya Kissoon, and Camari Koto focus on internal migration to urban informal settlements that are 'dangerous places' by many standards. Through a case study of two squatter settlements in Suva, Fiji, the authors seek to understand why people decide to leave their relatively safe rural homes and move instead to environmentally dangerous informal settlements.

While much research on the environment-migration nexus assumes that people migrate from areas threatened by climate change to safer, less exposed areas, the chapter shows how this assumption is not necessarily valid. Safety has different dimensions. Climate change does clearly affect urban squatter settlements such as 
those investigated by Weber, Kissoon, and Koto. Built in mangrove forests and consisting of substandard housing, informal settlements are prone to tidal flooding that climate change is expected to worsen, and are likely to experience severe damage in case of tropical cyclones that are also expected to worsen under climate change. Inhabitants of informal settlements are aware of these current and future threats - but security has many dimensions. As the chapter describes, urban areas offer more, and more diverse, livelihood opportunities, which can help improve settlers' economic security. Similarly, adverse environmental conditions also provide security: security from the threat of eviction. The worse conditions are, the less likely that the government or the private sector will seek to develop property. As Suva - like other urban areas in the Pacific Islands - is growing, formerly marginal areas become prime property. In the eyes of informal settlers, the threat of property development, and therefore eviction, is more urgent and severe than the threat of climate change.

Elfriede Hermann and Wolfgang Kempf examine how options of migration and in situ adaptation are debated in Kiribati. While the central Pacific atoll state of Kiribati is different from Fiji in many ways, the country can certainly also be considered a place that is particularly vulnerable to the consequences of climate change. With frequent flooding, widespread erosion and limited freshwater resources, Kiribati may become uninhabitable in the long run according to some climate science projections. Migration has thus been discussed in Kiribati as a form of long-term adaptation in connection with in situ adaptation for the short and medium term.

Hermann and Kempf draw on their extensive field work in Kiribati to examine how these discourses have developed, and how different governments - that of Anote Tong (2003-2016) and that of Maamau (since 2016) - have engaged with, or distanced themselves from, debates on migration as adaptation. The cultural conception of land that links land and people, as well as imaginations of the future help us to make sense of local understandings and discourses of climate change adaptation and migration. In particular, the authors use the notion of "politics of hope" to compare and contrast the divergent approaches to coping with the consequences of climate change of the Tong and Maamau governments. While both governments have always insisted on the need for strong mitigation, and hope for a future of the I-Kiribati on their own lands, they relate to migration in different ways. For the Tong government, migration/relocation may become inevitable in the long term, which is why it began to conceptually prepare for this worst-casescenario by developing the concept of "migration with dignity". It hoped that such steps would ensure the survival of I-Kiribati community and identity. In contrast, the current Maamau government refrains from debating relocation, and instead seeks to develop Kiribati in situ, including through land reclamation and coastal protection. It hopes that individual temporary migration abroad, and migrants' remittances, as well as urban-rural migration from the main island of South Tara- 
wa to outer islands, will support this in situ development. Culturally specific notions of land, people, and the future underpin both these approaches to migration, for the objective of both is to ensure the long-term survival and wellbeing of the IKiribati as a people.

While much literature on climate migration focuses on atoll countries like Kiribati, migration and mobility are also present in other SIDS. Ximena Flores Palacios examines local perceptions of and experiences with migration in Lotofaga, a coastal village on the southern coast of Upolu, Samoa's main island. Through anthropological fieldwork in Lotofaga, Samoa's capital Apia, and the Samoan community in Auckland, New Zealand, Flores Palacios seeks to understand how and where people move, and to what extent climate change affects and changes past mobility patterns.

Lotofaga villagers are resilient, and they are mobile; strong social networks, based on extended families - 'aiga - and local traditional knowledge and fa'a Samoa, the Samoan way of life, underpin Samoans' resilience. Migration is part of this; many extended families include members in Apia and abroad, mainly New Zealand. While economic factors have so far dominated migration decisions, whether to Apia or overseas, climate change is increasingly coming into play. Climate change, mostly sea-level rise and associated coastal flooding, also pushes villagers inland, with new houses being built further away from the coasts.

Much of Lotofagans' migration to date has been based on economic opportunities, although, as the chapter emphasises, migration is a complex process that results from a variety of factors. Disentangling climate change from this mix of factors is extremely difficult. This chapter addresses this difficulty and complexity through a focus on local voices and perspectives, which often reflect a more holistic understanding of people's actions on climate change and resilience.

Centering island perspectives, be they from Samoa, the larger Pacific, or the Caribbean and Indian Ocean, was also the purpose of the workshop we organised in Hannover, and the present publication that results from this workshop. We hope that, by bringing together work from different island regions and from different academic disciplines, we can offer a more nuanced picture of climate change adaptation in islands, one that highlights the specificities of island contexts and their diversity. Clearly, climate change presents extreme challenges to islands and islanders, and many barriers - such as limited resources, small and siloed administrations, and remoteness - make it difficult to implement context-specific, suitable, and sustained adaptation strategies. But despite these challenges and despite their diversity, islands and island societies share a great resilience in the face of change, as the contributions to this volume illustrate. 


\section{Bibliography}

Adger, W. N. (2006). Vulnerability. Global Environmental Change, 16, 268-281.

Adger, W. N., Barnett, J., Brown, K., Marshall, N., \& O’Brien, K. (2013). Cultural dimensions of climate change impacts and adaptation. Nature Climate Change, 3, 112-117.

Barnett, J., \& Campbell, J. R. (2010). Climate change and small island states: Power, knowledge and the South Pacific. London: Earthscan.

Bassett, T. J., \& Fogelmann, C. (2013). Déjà vu or something new? The adaptation concept in the climate change literature. Geoforum, 48, 42-53.

Campbell, J. R. (2009). Islandness: Vulnerability and resilience in Oceania. Shima: The International Journal of Research into Island Cultures, 3(1), 85-97.

Campbell, J. R. (2010). Climate change and population movement in Pacific Island countries. In B. Burson (Ed.), Climate change and migration: South Pacific perspectives (pp. 29-50). Wellington: Institute of Policy Studies, Victoria University of Wellington.

Campbell, J. R. (2014). Climate-change migration in the Pacific. Contemporary Pacific, 26(1), 1-29.

De Souza, R.-M., Henly-Shepard, S., McNamara, K. E., \& Fernando, N. (2015). Re-framing island nations as champions of resilience in the face of climate change and disaster risk. UNU-EHS Working Paper No. 9. Bonn: Livelihood Resilience in the Face of Global Environmental Change.

Dornan, M., \& Pryke, J. (2016). Foreign aid to the Pacific: Trends and developments in the twenty-first century. Asia \& the Pacific Policy Studies, 4(3), 386-404.

Eriksen, S., Nightingale, A. J., \& Eakin, H. (2015). Reframing adaptation: The political nature of climate change adaptation. Global Environmental Change, 35, 523-533.

Farbotko, C. (2005). Tuvalu and climate change: Constructions of environmental displacement in the Sydney Morning Herald. Geografiska Annaler, 87 B(4), 279-293.

Farbotko, C. (2010). Wishful sinking: Disappearing islands, climate refugees and cosmopolitan experimentation. Asia Pacific Viewpoint, 51(1), 47-60.

Farbotko, C. (2012). Skilful seafarers, oceanic drifters or climate refugees? Pacific people, news value and the climate refugee crisis. In K. Moore, B. Gross, \& T. Threadgold (Eds.), Migrations and the media (pp. 119-142). New York: Peter Lang.

Grothmann, T., \& Patt, A. (2005). Adaptive capacity and human cognition: The process of individual adaptation to climate change. Global Environmental Change, 15.

Keck, M., \& Sakdapolrak, P. (2013). What is social resilience? Lessons learned and ways forward. Erdkunde, 67(1), 5-19. 
Klepp, S., \& Chavez-Rodriguez, L. (2018). Governing climate change: The power of adaptation discourses, policies and practices. In S. Klepp \& L. ChavezRodriguez (Eds.), A critical approach to climate change adaptation: Discourses, policies and practices (pp. 3-34). London and New York: Routledge.

Klöck, C., Debelts, H., \& Fink, M. (2019). Conference report: "Dealing with climate change on small islands - Towards effective and sustainable adaptation?". Pacific Geographies, 51, 23-25.

Klöck, C., \& Nunn, P. D. (2019). Adaptation to climate change in Small Island Developing States: A systematic literature review of academic research. Joumal of Environment \& Development, 28(2), 196-218.

Lauer, M. (2017). Changing understandings of local knowledge in island environments. Environmental Conservation, 44(4), 336-347.

Lee, T. M., Markowitz, E. M., Howe, P. D., Ko, C. Y., \& Leiserowitz, A. A. (2015). Predictors of public climate change awareness and risk perception around the world. Nature Climate Change, 5(11), 1014.

McNamara, K. E., \& Des Combes, H. J. (2015). Planning for community relocations due to climate change in Fiji. International Journal of Disaster Risk Science, 6(3), 315-319.

Mercer, J., Dominey-Howes, D., Kelman, I., \& Lloyd, K. (2007). The potential for combining indigenous and western knowledge in reducing vulnerability to environmental hazards in Small Island Developing States. Environmental Hazards, 245-256.

Mikulewicz, M. (2018). Politicizing vulnerability and adaptation: On the need to democratize local responses to climate impacts in developing countries. Climate and Development, 10(1), 18-34.

Mimura, N., Nurse, L., McLean, R., Agard, J., Briguglio, L., Lefale, P., . . Sem, G. (2007). Small islands. In M. L. Parry, O. F. Canziani, J. P. Palutikof, P. J. van der Linden, \& C. E. Hanson (Eds.), Climate Change 2007: Impacts, adaptation and vulnerability. Contribution of Working Group II to the Fourth Assessment Report of the Intergovernmental Panel on Climate Change (pp. 688-716). Cambridge: Cambridge University Press.

Moncada, S., Briguglio, L. P., Bambrick, H., \& Kelman, I. (2018). Guest editorial for the Special Issue on "Development and Climate Change in Small Island Developing States". International Journal of Climate Change Strategies and Management, , 10(2), 214-216.

Nalau, J., Becken, S., Schliephack, J., Parsons, M., Brown, C., \& Mackey, B. (2018). The role of indigenous and traditional knowledge in ecosystem-based adaptation: A review of the literature and case studies from the Pacific Islands. Weather, Climate, and Society, 10, 851-865.

Nunn, P. D., \& Kumar, R. (2006). Coastal history in the Asia-Pacific region. In N. Harvey (Ed.), Global change and integrated coastal management: The Asia-Pacific region (pp. 93-116). Berlin: Springer. 
Nunn, P. D., \& Kumar, R. (2018). Understanding climate-human interactions in Small Island Developing States (SIDS): Implications for future livelihood sustainability. International Journal of Climate Change Strategies and Management, 10(2), 245-271.

Nurse, L., McLean, R., Agard, J., Briguglio, L., Duvat, V. K. E., Pelesikoti, N., . . . Webb, A. (2014). Small islands. In V. R. Barros, C. B. Field, D. J. Dokken, M. D. Mastrandrea, K. J. Mach, T. E. Bilir, M. Chatterjee, K. L. Ebi, Y. O. Estrada, R. C. Genova, B. Girma, E. S. Kissel, A. N. Levy, S. MacCracken, P. R. Mastrandrea, \& L. L. White (Eds.), Climate Change 2014: Impacts, adaptation, and vulnerability. Part B: Regional aspects. Contribution of Working Group II to the Fifth Assessment Report of the Intergovernmental Panel on Climate Change. Cambridge: Cambridge University Press.

O’Brien, K., \& Wolf, J. (2010). A values-based approach to vulnerability and adaptation to climate change. WIREs Climate Change, 1(2), 232-242.

Overton, J., Prinsen, G., Murray, W. E., \& Wrighton, N. (2012). Reversing the tide of aid: Investigating development policy sovereignty in the Pacific. Journal de la Société des Océanistes, 135(2), 229-242.

Ratter, B. M. W. (2018). Geography of small islands: Outposts of globalisation. Cham: Springer.

UNESCO. (2017). Small Island Developing States (SIDS). Retrieved from http://www.unesco.org/new/en/natural-sciences/priorityareas/sids/environmental-resilience-and-sustainability/.

Walshe, R. A., \& Stancioff, C. E. (2018). Small island perspectives on climate change. Island Studies Journal, 13(1), 13-24.

Zickgraf, C. (2018). Immobility. In R. McLeman \& F. Gemenne (Eds.), Routledge handbook of environmental displacement and migration. London: Routledge. 